\title{
Comparison of sperm viability in three male age of Drosophila melanogaster exposure of cold temperature
}

\author{
*Abolhasan Rezaei \\ *Department of Genetics-School of Basic Science, Tonekabon Branch, Islamic Azad \\ University, Tonekabon, Iran \\ Mailing Address: Islamic Azad University Tonekabon Branch-Iran. P.O. Box \\ 4864161187, Tonekabon, Iran. \\ a.rezaei@tonekaboniau.ac.ir
}

\begin{abstract}
Male Drosophila melanogaster, like males of many other animal species, male age and temperature affected the sperm number. Here we use Drosophila melanogaster males of different ages and decreasing temperature on the sperm number, to investigate the role of aging and temperature affected to sperm transferred to female during mating. The male ages were used to show that while maximize sperm number in young (2-3 days)and middle age (27-28 days) was contributed but mean value of sperm number between fifty replicate was different and also the results of one way ANOVA were significant between three age classes. Sperms after mating soon counted from female reproductive system, the results are shown, mean value of sperms when males exposed to cold temperature $\left(15^{\circ} \mathrm{C}\right)$ in young and middle aged, sperm number was around 4000, and old male aged (952-53 days) around 2000, these results demonstrate that viability of sperm produce in males after 27- 28 days, will be reduced more than young to middle aged.
\end{abstract}

Keywords: Drosophila melanogaster, Male age, sperm counting, Cold temperature

\section{INTRODUCTION}

In insects, delivering sperm to females which will use them in return is only one component of a male's reproductive success. The sperm in males after mating with females can storage in genital tract for a few days to years. (Reviewed in Birkhead and Møller 1998; Neubaum and Wolfner 1999a). Sperms transferred by via spermatophore can be lost easily if the package is removed either by the female or by a rival male, before sperm have moved from the package into the female's sperm (Kotrba 1996; Birkhead and Møller 1998). In addition, seminal fluid also is important in storage and viability sperms, male reproductive success in Drosophila melanogaster (Reviewed by Wolfner 1997).The sperms will storage in genital tract, the seminal receptacle is a long, that branches from the posterior end of the common oviduct (Miller 1950). It is an organ that will save around 80 to $90 \%$ sperm during mating (Fowler et al., 1968). The primary storage organ seminal receptacle is an elongated tubule with an extremely narrow lumen through which the sperm enter for storage. Many factors are known to influence the male success at sperm production; various male oriented parameters have been measured with respect to sperm competitive ability. For instance, it has been measured in insects, especially, Drosophilidea that Copulation duration has also been studied rather intensively in the Drosophilidae (Gromko et al., 1984; Saul et al., 1988; Gilchrist, 2000; Bundgaard and Barker, 2000). Male size (Pitnick and Markow, 1994; Zeh et al., 1997; Arnqvist and 
Danielsson, 1999), sperm size and allocation (Pitnick and Markow, 1994),and accessory glands proteins (Acps) (Wolfner, 1997). Recently, investigated that females play considerable more than the passive role they were once ascribed (Gowaty, 1994). The suggestion is that females might influence males during and after mating as cryptic female choice (Eberhard and Cordero 1995; Eberhard, 1996, 2000). Price et al., 1999, proposed female age (11 day old) may already be effective senescing physiologically. In the present study we used influence of aging and temperature on the sperm counting. In normality temperature condition male 7 days aged old will produce 4000 to 6000 sperm in single mating (Gilbert et al., 1981), here we aimed at discussing the among of variation sperm number in different male ages (young, middle and old), moreover the effect of temperature on the among sperm number in males, which males ability adapted under exposure of cold temperature.

\section{MATERIALS AND METHODS}

Drosophila stocks: The isofemale line of Drosophila melanogaster, Oregan K was collected from the national Drosophila stock center, Department of Zoology, Mysore, India. These flies were used for the sperm counting from different male aged flies. The flies were cultured by using wheat cream agar medium at $15^{\circ} \mathrm{C} \pm 1^{\circ} \mathrm{C}$ with a relative humidity of $70 \%$. 20 flies per quarter pint bottle were maintained using 12:12 hour light / dark cycle. From these stocks virgin females and unmated males were isolated and maintained separately in vials $\left(3^{\prime} \times 1^{\prime}\right)$ with a group of four flies per vial and aged of required for sperm counting.

Sperm counting: Experiments were designed so that the flies were aged for male 2-3 days from the day of eclosion were collected to mate with 5-6 days virgin female. The sperm counting was done from female after mating with them. The female flies were anaestithesied with ether. The sperm storage in female genital tracts was dissected, fixed and stained with $2 \%$ orcein in $60 \%$ acetic acid (Gilbert 1981; Gilbert et al., 1981) and counted at $\times 100$ magnification using phase contrast microscopy (Fig.1).

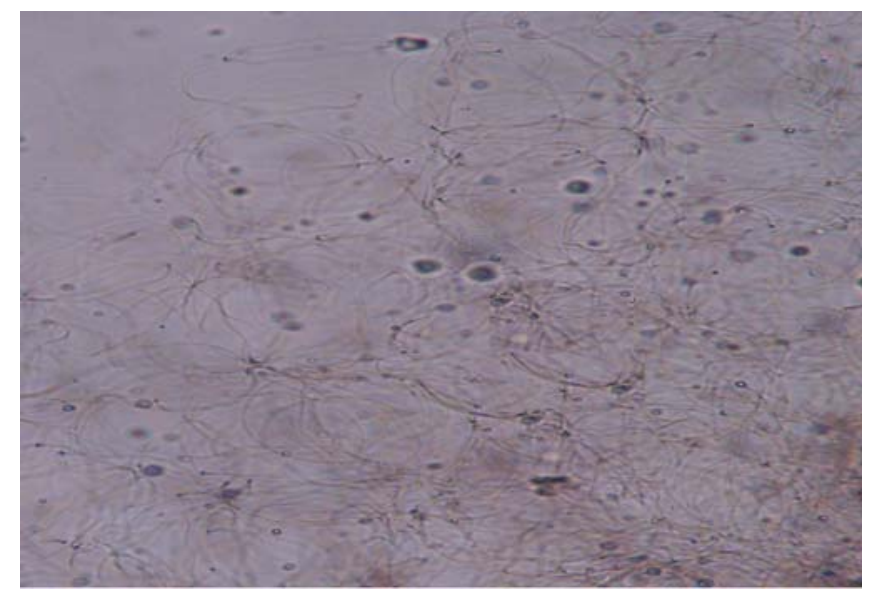

Fig. 1: The results of sperm staining when dissected genital tract from females. There was a mass sperms for single mating.

The flies after mating were kept for 27-28 days, again these flies were mated with 5-6 days females and were dissected genital tract and sperm counted, also the males mated were kept for 52-53 days, after that again male flies were mated with 5-6 days females and sperm counted. So, we had three ages male (young, middle and old) that mated in three times with females. 
Statistical analysis: Data was analyzed by SPSS software (version of 10.5). The total sperm stored was calculated by ANOVA test.

\section{RESULTS}

Male age and different temperature: In this experiment we had three male age classes (young, middle and old) that exposed to the cold temperature $\left(15^{\circ} \mathrm{c}\right)$, diagram 1 results are shown:

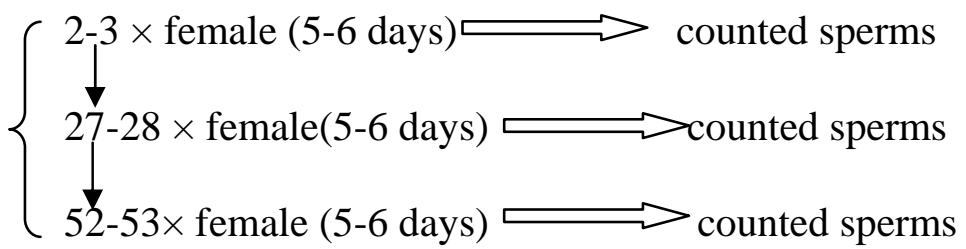

Diagram 1: The schedule of male mating of three male ages with females 5-6 days that were dissected female genital tract and counted sperms.

Sperm counting: We used the temperature of cold for males, our results provide direct experimental evidence in three different male ages (young, middle and old), which sperm is transferred from a sperm quality and quantity in the Drosophila melanogaster. The females were dissected at interval ranging from soon after mating to 45 minutes that female by the male, which included interrupted copulations. The results are shown; there is a high degree of individual variation in the sperm storage process. The results of mean value analyzed by SPSS software (version 10.1), (Table 1). Sperm number when greater than 2000, was estimated by measuring the area covered by the uteral sperm mass that counted sperms density at random points in the mass (Fig. 2). Receptacle and spermathecal sperm were counted directly. The entire counting time for a specimen ranged from 15 to 45 minutes. Results also were analyzed by ANOVA one way.

Table 1: The results mean value, maximum and minimum variation between three male age classes (young, middle and old) when exposed to cold temperature. There were different mean values between male ages.

\begin{tabular}{|c|c|c|c|c|c|c|c|c|}
\hline \multicolumn{9}{|c|}{$\begin{array}{c}\text { Descriptives } \\
\text { Sperm No. }\end{array}$} \\
\hline & \multirow{2}{*}{$\mathrm{N}$} & \multirow{2}{*}{ Mean } & \multirow{2}{*}{ Std. Deviation } & \multirow{2}{*}{ Std. Error } & \multicolumn{2}{|c|}{ 95\% Confidence Interval for Mean } & \multirow{2}{*}{ Minimum } & \multirow{2}{*}{ Maximum } \\
\hline & & & & & Lower Bound & Upper Bound & & \\
\hline 1.00 & 50 & 4944.0000 & 920.05102 & 130.11486 & 4682.5244 & 5205.4756 & 550.00 & 5600.00 \\
\hline 2.00 & 50 & 4435.6000 & 452.29194 & 63.96374 & 4307.0601 & 4564.1399 & 3000.00 & 5600.00 \\
\hline 3.00 & 50 & 2758.0000 & 549.24438 & 77.67488 & 2601.9065 & 2914.0935 & 2000.00 & 4000.00 \\
\hline Total & 150 & 4045.8667 & 1150.25716 & 93.91810 & 3860.2833 & 4231.4501 & 550.00 & 5600.00 \\
\hline
\end{tabular}

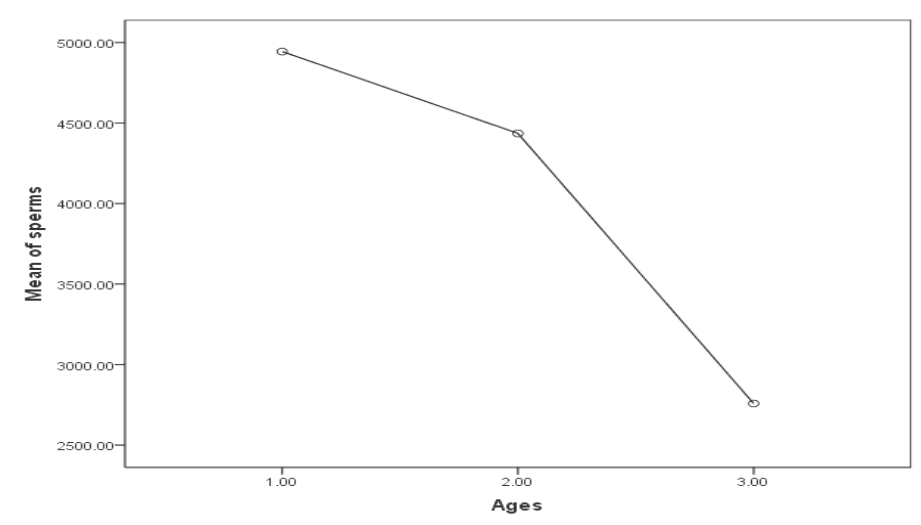

Fig. 2: The results of mean plots for sperm number between three male age classes (young, middle and old) are shown, there was a high variation regarding sperm number between young, middle with old age classes. 
Table 2 lists have been descriptive minimum and maximum in three age classes (young, middle and old), moreover, minimum of sperm counted in young aged male was 550, but mean of value for young male aged more than middle and old aged. The results of ANOVA analysis and Tukey post hoc pair wise were significant between age and sperm number. $\mathrm{P}$ value $<0.00$. (Table 3 ).

Table 2: The results of ANOVA variation between three male age groups, that were significant between groups. $\mathrm{P}$ value $<0.00$.

ANOVA

Sperms
\begin{tabular}{|l|r|r|r|r|r|}
\hline & Sum of Squares & \multicolumn{1}{|c|}{ df } & Mean Square & \multicolumn{1}{c|}{ F } & \multicolumn{1}{c|}{ Sig. } \\
\hline Between Groups & $1.309 \mathrm{E} 8$ & 2 & $6.543 \mathrm{E} 7$ & 145.103 & .000 \\
Within Groups & $6.628 \mathrm{E} 7$ & 147 & 450910.422 & & \\
Total & $1.971 \mathrm{E} 8$ & 149 & & & \\
\hline
\end{tabular}

Table 3: The results of Tukey pair wise between three male age classes. Mean for groups in homogeneous subsets are displayed.

\begin{tabular}{|c|c|c|c|c|}
\hline \multirow[t]{2}{*}{ Ages } & \multirow[b]{2}{*}{$\mathrm{N}$} & \multicolumn{3}{|c|}{ Subset for alpha $=0.05$} \\
\hline & & 1 & 2 & 3 \\
\hline $\begin{array}{l}3.00 \\
2.00 \\
1.00\end{array}$ & $\begin{array}{l}50 \\
50 \\
50\end{array}$ & 2758.0000 & 4435.6000 & 4944.0000 \\
\hline
\end{tabular}

a. Uses Harmonic Mean Samlpe Size $=50.00$

\section{DISCUSSION}

In this study we used three age classes for discuss of effect of aging on the amount of sperm produce and sperm numbering. A male's mating success and male mating ability were measured by the number of sperms that produced by different ages when exposure to cold temperature, in fact we aimed at which age (young, middle and old) was adapted on the cold temperature. To gain a better understanding of how males maximize the possibility that their sperm will be used. We demonstrated that males are capable of transferring sperm when exposure to cold temperature than normal temperature condition, that is important because Kaplan et al., 1962, Gilbert et al., 1981, show, the minimum sperm number when male flies had 7 days aged old and exposed to normal temperature was around 5800 sperm in during single mating. In this study maximum sperm produced in young (2-3 days) and middle aged (27-28 days), is around 5800 number, but the mean of sperms was different between young and middle aged, in fact male's ability to produce maximum sperms until 27-28 days is the same with male young age, then the rate of production of sperm will be reduced. In other hand, while the focus has been on identifying male components required for sperm storage in females, it has been recently shown that females exert some influence on the fate of the sperm in their genital tract. Demonstrating of sperm dependence of female receptivity both during and after mating (e.g., Pyle and Gromko, 1978; Thomhill and Alcock, 1983; Arthur et al., 1998; Bloch-Qazi et al., 1998; Hellriegel and Ward, 1998; Hellriegel and Bernasconi, 2000; Hosken and Ward, 2000).), is similar to the present analysis, which is based on female age, in this study we used 5-6 female days aged old that has effect on the mating latency and copulation duration, this seems to be an entirely reasonable assumption for male young and middle aged. Also Clark and Begun (1998) demonstrated that sperm 
competition is affected by the genotype of the female. In this study however the female ages were similar between three male age classes, but also female was accumulated good genes from the young and middle aged. (Prathibha and Krishna, $2010)$. In this study we used males exposed to cold temperature $\left(15^{\circ} \mathrm{c}\right)$. Temperature is one of the most important environmental factors which has effects on some fitness traits, such as viability and reproductive performance (David, Allemand, Herrewege \& Cohet, 1983). In the female among of oviposition when female exposure to cold temperature $\left(12-20^{\circ} \mathrm{C}\right)$ more than high temperature (McKenzie, 1975; Parsons, 1978), however the males affected the oviposition of females but also males young and middle aged are more affected on the male old aged. Our results are shown, the among of produce sperm in 2-3 days male aged more than male 27- 28 days aged, however maximize production of sperm between young and middle was similar but the mean value was different, in figure 2 is shown that the length of production sperm between young and middle is less but between young, middle and old was very high, these results denoted males after 27 -28 day are more affected in the cold temperature also aging the cause of reduction sperm viability in male old days.

\section{ACKNOWLEDGMENTS}

This work had financially supported by the Research Council of Islamic Azad University Tonekabon Branch, Iran.

\section{REFERENCES}

Arthur, B. I., E. Hauschteck-Jungen., R. Nothiger., P. I. Ward. 1998. “A female nervous system is necessary for normal sperm storage in Drosophila melanogaster: a masculinized nervous system is as good as none.” Proceedings of the Royal Society of London Series B-Biological Sciences. 265(1407): 17491753.

Arnqvist, G. and I. Danielsson. 1999. "Postmating sexual selection: the effects of male body size and recovery period on paternity and egg production rate in a water strider.” Behavioral Ecology. 10(4): 358-365.

Birkhead, T.R., Møller, A.P. 1998. Sperm Competition and Sexual Selection. London: Academic Press.

Bloch-Qazi, M. C., J. R. Aprille and S. M. Lewis. 1998. "Female role in sperm storage in the red flour beetle, Tribolium castaneum." Comparative Biochemistry and Physiology a-Molecular and Integrative Physiology. 120(4): 641-647.

Bernasconi, G., Hellriegel, B., Heyland, A., P.I.Ward. 2002. Sperm survival in the female reproductive tract in the fly Scathophaga stercoraria (L.). J. Insect Physiol. 48: 197-203.

Clark, A. G. and D. J. Begun. 1998. "Female genotypes affect sperm displacement in Drosophila.” Genetics. 149(3): 1487-1493.

David, J. R., Allemand, R., J. Van Herrewege., Y. Cohet. 1983. Ecophysiologie: abiotic factors. In: M. Ashburner, H.L. Carson and J.N. Thompson, (Eds.) Genetics and biology of Drosophila . (pp. 105-170) Academic Press, New York.

Eberhard, W. G. 1996. Female control: sexual selection by cryptic female choice. Princeton, NJ, Princeton University Press.

Eberhard, W. G. 2000. "Criteria for demonstrating postcopulatory female choice." Evolution. 54(3): 1047-1050. 
Eberhard, W. G. and C. Cordero. 1995. "Sexual selection by cryptic female choice on male seminal products a new bridge between sexual selection and reproductive physiology.” Trends in Ecology \& Evolution. 10(12): 493-496

Fowler, G. L. 1973. Some aspects of the reproductive biology of Drosophila: sperm transfer, sperm storage and sperm utilization. Adv. Genet. 17: 293-360.

Gilbert, D. 1981. Ejaculate esterase-6 and initial sperm use by female Drosophila melanogaster. J Insect Physiol. 27: 641-650.

Gilbert, D. G., R. C. Richmond and K. B. Sheehan. 1981. Studies of esterase 6 in Drosophila melanogaster. V. Progeny production and sperm use in females inseminated by males having active or null alleles. Evolution. 35: 21-37.

Gromko, M. H. and P. D. Gerhart.1984. "Increased density does not increase remating frequency in laboratory populations of Drosophila melanogaster." Evolution. 38(2): 451-455.

Gilchrist, A. S. and L. Partridge. 2000. "Why it is difficult to model sperm displacement in Drosophila melanogaster: The relation between sperm transfer and copulation duration.” Evolution. 54(2): 534-542.

Gowaty, P. A. 1994. "Architects of sperm competition." Trends in Ecology \& Evolution. 9(5): 160-162.

Hellriegel, B. and P. I. Ward. 1998. "Complex female reproductive tract morphology: its possible use in postcopulatory female choice.” Journal of Theoretical Biology 190: 179-186.

Hellriegel, B. and G. Bernasconi. 2000. "Female-mediated differential sperm storage in a fly with complex spermathecae, Scatophaga stercoraria." Animal Behaviour. 59: 311- 317.

Hosken, D. J. and P. I. Ward. 2000. "Copula in yellow dung flies (Scathophaga stercoraria): investigating sperm competition models by histological observation.” Journal of Insect Physiology. 46(10): 1355-1363.

Kotrba, M. 1996. "Sperm transfer by spermatophore in Diptera: New results from the Diopsidae.” Zoological Journal of the Linnean Society. 117(3): 305-323.

Kaplan, W. D., V. E. Tinderholt and D. H. Gugler. 1962. The number of sperm present in reproductive tracts of $D$. melanogaster Cell females. Dros. Info. Serv. 36: 82.

Miller, A. 1950. The internal anatomy and histology of the imago of Drosophila melanogaster, pp. 421-534 in The Biology of Drosophila,. edited by M. Demerec. John Wiley \& Sons, New York.

McKenzie, J. A., 1975. The influence of low temperature on survival and reproduction in populations of Drosophila melanogaster. Aust. J. Zool. 23: 237247.

Neubaum, D.M., M.F. Wolfner. 1999. Mated Drosophila melanogaster females require a seminal fluid protein, Acp36DE, to store sperm efficiently. Genetics. 153:845-857.

Pitnick, S. and T. A. Markow. 1994. "Male gametic strategies - sperm size, testes size, and the allocation of ejaculate among successive mates by the sperm- limited fly Drosophila pachea and its relatives.” American Naturalist. 143(5): 785-819.

Pitnick, S. and T. A. Markow. 1994. "Large male advantages associated with costs of sperm production in Drosophila hydei, a species with giant sperm.” Proceedings of the National Academy of Sciences of the United States of America. 91(20): 9277-9281.

Pyle, D. W., and M. H. Gromko. 1978. Repeated mating by female Drosophila melanogaster: the adaptive importance. Experientia. 34: 449-450. 
Parsons, P. A. 1978. Boundary conditions for Drosophila resource utilization in temperate regions, especially at low temperatures. Am. Nat., 112: 1063-1074.

Prathibha, M., M.S. Krishna. 2010. Greater mating success of middle-aged females in D. ananassae. Zoological Studies. 49(6): 805-814.

Saul, S. H., S. Y. T. Tam and D. O. McInnis. 1988. "Relationship between sperm competition and copulation duration in the Mediterranean fruit fly (Diptera, Tephritidae).” Annals of the Entomological Society of America. 81(3): 498-502.

Thornhill, R., and J. Alcock. 1983. The Evolution of Insect Mating Systems. Harvard Univ. Press, Cambridge.

Wolfner, M. F. 1997. Tokens of love: functions and regulation of Drosophila male accessory gland products. Insect Biochem. Mol. Biol. 27: 179-192.

Zeh, J. A. and D. W. Zeh. 1997. "The evolution of polyandry .2. Postcopulatory defences against genetic incompatibility.” Proceedings of the Royal Society of London Series B-Biological Sciences. 264(1378): 69-75. 